\title{
Efigies para encarar la violencia entre hermanos: Una visión psicoanalítica
}

\section{Effigies to address violence among siblings: A psychoanalytic vision}

\author{
Ruth Vallejo Castro \\ María Guadalupe Tapia Fernández \\ Universidad Michoacana de San \\ Nicolás de Hidalgo
}

\begin{abstract}
Resumen
Este artículo parte de la tesis propuesta por Freud en torno al complejo de Edipo, el cual se reedita a partir del nacimiento de los hermanos hasta convertirse en un complejo familiar, que proporciona así un atisbo de lo que al complejo fraterno se refiere. La presente investigación, de carácter documental, muestra cómo surge la rivalidad fraterna y aporta algunos modos de resolución. Para lograr tal fin, se rastrearon desde la literatura cuatro narraciones que se analizaron bajo una mirada analítica: el mito de Edipo en Colono; los relatos bíblicos de Caín y Abel; Jacob y Esaú; y José y sus hermanos. Además, se formularon tres efigies o modelos de rivalidad fraterna, mismos que facilitan la mejor comprensión sobre el tema. El primer modelo llamado Rivalidad Consumada, se refiere a la escena donde se da muerte a uno o ambos contendientes. El segundo modelo llamado Rivalidad Tolerada es aquel en el cual los hermanos sobreviven, pero de una forma desnivelada o desigual. El tercer modelo, llamado Rivalidad Declinada, define la fratría en la que después de varios encuentros y desafíos se establece la reconciliación. En cada efigie se abordan los conflictos surgidos entre los hermanos, y sus modos de resolución, para finalmente establecer que el segundo y tercer modelo posibilitan el tránsito de la rivalidad fraterna a la fraternalización.

Palabras clave: complejo, rivalidad, efigies, fraterna, resolución.
\end{abstract}

Nota del autor

Ruth Vallejo Castro, Facultad de Psicología, Universidad Michoacana de San Nicolás de Hidalgo (UMSNH); María Guadalupe Tapia Fernández, Facultad de Psicología, UMSNH.

La correspondencia en relación con este artículo debe dirigirse a Ruth Vallejo Castro, Facultad de Psicología, UMSNH, calle Francisco Villa número 450, colonia Dr. Miguel Silva, C. P. 58110, Morelia, Michoacán, México.

Dirección electrónica: ruthvc4@hotmail.com 


\begin{abstract}
The investigation stems from reading the text Introductory Lectures on Psychoanalysis, with the idea expressed by Freud that the Oedipus complex is expanded to a family complex with the arrival of siblings, thus providing a glimpse into the fraternal complex. Therefore, the core objective of this desk research is to show how fraternal rivalry emerges, glimpsing some ways to solve it. To achieve this goal, four stories are tracked from literature: the myth of Oedipus at Colonus, the biblical accounts of Cain and Abel, Jacob and Esau, and Joseph and his brothers; these stories are analyzed with a psychoanalytic perspective, resulting in three effigies - or models- of fraternal rivalry that promote a wider understanding on the subject. The first model, named Consummated Rivalry, is the one concerning the scene where one or both contenders are killed; the second model, called Tolerated Rivalry, is that in which the siblings survive, but in uneven or unequal basis; and the third model, titled Declined Rivalry, defines that which manages to restore the brotherhood after several encounters and defiances. Each effigy deals with the conflicts arisen between siblings, as well as their solving ways, to finally establish that the second and third models are the ones that enable the transition from fraternal rivalry to brotherhood.

Keywords: complex, rivalry, effigies, fraternal, solving.
\end{abstract}

El rompimiento del tejido social cada vez es más penetrante, a la vez, la problemática familiar está amenazada al interior por su propia estructura; las dificultades económicas, políticas $\mathrm{y}$ sociales posibilitan que entre los miembros de la familia los lazos de unión y alianzas se debiliten, por lo tanto, el sostenimiento familiar se desmorona. Tal contexto lleva a preguntarnos: ¿qué pasa en la unión fraterna?, ¿cómo surge en el sujeto la rivalidad fraterna, y la forma de establecer el tránsito para tolerarla o declinarla?

Por lo anterior, se busca descubrir las formas de rivalidad fraterna, al establecer la resolución a partir de tres modos de operar, con base en la hermenéutica según el sentido gramatical en el análisis del mito de Edipo en Colono, los relatos bíblicos de Caín y Abel, Jacob y Esaú, José y sus hermanos, desde la interpretación como método propio del psicoanálisis. Se plantea la resolu- ción del complejo fraterno a través de tres efigies y se reconstruye la forma que tiene el sujeto de encarar la agresividad y dominarla a pesar de todas las vicisitudes; en las dos últimas efigies se establece la reconciliación de los hermanos y en la tercera la declinación de la rivalidad fraterna a través del acto filial.

En lo que respecta a la primera efigie, se visualiza como consecuencia funesta en caso de fallar el establecimiento del lazo fraterno, ya que la reconciliación se produce para evitar el asesinato y el odio fratricida. Los procesos de reconciliación con el hermano ponen sobre la pista un destino fundamental del vínculo fraterno: el lazo social.

\section{Desarrollo: Efigies de la rivalidad fraterna}

Al nacimiento de un hermano, el complejo fraterno se instaura y desencadena una serie de sucesos ante la intrusión perpetrada y contra 
la omnipotencia del hijo único, la aparición es tomada como una afrenta contra su narcisismo, y deja una herida que necesita ser resarcida; las consecuencias de tal intromisión son la hostilidad o la seducción, la agresión o la reconciliación.

Freud (1900/1990) considera que "el niño es absolutamente egoísta, siente con intensidad sus necesidades y se afana sin miramientos por satisfacerlas, en particular contra sus rivales, los otros niños, y en primer lugar contra sus hermanos" (p. 260), por tanto, para la mejor comprensión del complejo fraterno en relación con su forma de resolución se ilustrará bajo tres efigies de rivalidad fraterna, las cuales son una propuesta desde una propia mirada.

El término efigie se refiere a una imagen, copia o imitación de una persona; viene del latín effigies y, así como fingere remite a la palabra ficción. El sentido primario de fingere es modelar, mientras que el de effigies alude propiamente a una reproducción, una imagen modelada o ficticia sacada de un objeto real (Etimología, 2012).

Durante el surgimiento del complejo fraterno, el lugar que se otorga al sujeto en el orden de los nacimientos es el de heredero o usurpador. Lo que expresa Hegel (como se citó en Trías, 2005) sobre la exaltación de la autoconciencia se vincula con lo planteado, dado que ésta inicia al fundirse el sujeto y el objeto en una unidad, una identidad, la unidad desdoblada y la identidad desgarrada, ya que las dos partes son confrontadas. Este mismo término, retomando a
Hobbes (como se citó en Trías, 2005), da cuenta de la unidad desdoblada:

Son, pues, dos partes que se enfrentan, la una con la otra, siendo como son idénticas. Sólo de la lucha a muerte puede determinarse y decidirse cuál de las dos es libre, o cuál de las dos es capaz de independizarse de la otra. (p. 66).

Se lleva a cabo una lucha a muerte por el reconocimiento, misma que exige liberar ese singular combate de un individuo contra otro, donde en plena relación especular se determina quién de los dos es independiente y quién es dependiente.

Las soluciones son varias: la destrucción de ambos contendientes, que impide cualquier prosecución de esta dialéctica del reconocimiento; la destrucción de uno de ellos y el mantenimiento de vida de aquél que sobrevive; o la supervivencia de los dos, pero de forma desnivelada y desigual, ya que uno aparece entonces señalado como amo, y el otro en cambio (el que reconoce al anterior como tal amo y señor). (Hobbes, como se citó en Trías, 2005, p. 69).

Es innegable que el relevo del principio de placer por el principio de realidad puede ser responsabilidad de una pequeña parte de las experiencias del displacer, porque ciertas pulsiones se muestran inconciliables con las restantes y, entonces, son rechazadas por el proceso de represión. Estas se detienen en estadios inferiores del desarrollo psíquico y se 
les corta desde el comienzo la posibilidad de alcanzar satisfacción.

Al especular acerca de las pulsiones de vida y de muerte, aparecen en dicha acción procesos tan extraños e inimaginables como que una pulsión sea forzada a salir fuera por otra o que se vuelva del yo al objeto, y cosas parecidas. El propio amor de objeto enseña otra polémica: la que media entre el amor (ternura) y odio (agresión).

Qué mejor forma de abordar la primera efigie, Rivalidad Consumada, que sustentarlo a través de las pulsiones de vida y de muerte, ya que el yo está sometido a la acción eficaz de las pulsiones, lo mismo que el ello. Ambas pulsiones se comportan de tal manera que aspiran a restablecer un equilibrio por el estado perturbador en la génesis de vida, y ésta es la causa de que la pulsión de muerte continúe su pugna.

Esquilo concilia el pasado y el presente de la leyenda de Edipo, el inicio y el final, al concebirla como una serie de sucesos encadenados. En la primera generación, Layo comete una falta imperdonable: desobedecer a Apolo, quien le anunció que solo sin engendrar salvaría a la ciudad, pero Layo hizo oídos sordos y engendró a Edipo, de ahí una estela de infortunios; en la segunda generación, el parricidio y el incesto cometidos por Edipo, constituyen el efecto de esta falta inicial; la tercera generación, Eteocles y Polinice representan el efecto de la maldición paterna de Edipo.

\section{Un reino destrozado: Polinice y Eteocles}

Edipo después de haber quedado ciego fue encarcelado por sus hijos. Un día Polinice y
Eteocles le enviaron a su padre los muslos de un animal, que eran los desechos de un sacrificio, Edipo, ante esta humillación y burla los maldijo con la disputa del reinado de Tebas, se daba por hecho el deseo de muerte para ambos. La segunda vez que ratificó su maldición contra sus hijos fue cuando Polinice iba a pedir ayuda a su padre para rescatar el trono usurpado: la respuesta anunciada era una lucha a muerte donde ambos contendientes morirían.

La trama gira en torno al papel de la envidia desenmascarada, que lleva a consecuencias nefastas; indudablemente fue la envidia de Eteocles y Polinice por retener el trono que no vacilaron un instante en matar a su propio hermano, sentían uno por el otro odio y rencor que los dominaba hasta su último aliento de vida. Frente a la situación de identificación narcisista, el yo enfrenta una polaridad en la imagen especular: mantener su precaria unidad o fragmentarse, se siente amenazado con el riesgo de su fragmentación, por lo tanto, existe una lucha a muerte por el reconocimiento.

La tragedia comienza con el enfrentamiento fraterno y feroz de sus hermanos, quienes se dan muerte el uno al otro; mueren en desigualdad de honores, Eteocles, el héroe, fue enterrado con ritos fúnebres honrosos, Polinice, el traidor, destinado al destierro y, bajo el sol, al apetito de las bestias. Eteocles se concebía a sí mismo como el doble de su hermano y rival, lo que muestra las relaciones de tensión, entonces, Polinice mata a Eteocles por orgullo y éste mata a aquél por traidor. 
El hijo único se parece a un monarca súbitamente despojado de sus prerrogativas y que presencia la transferencia de su cetro en las manos de un usurpador. Así, más de un niño que se consideraba sólidamente reinante en el amor inquebrantable de los padres, fue arrojado de un solo golpe de todos los cielos, expulsado de todos los paraísos de su omnipotencia presuntuosa a la llegada del hermano.

El rechazo del objeto no querido es un gesto intensamente destructivo, encuentra su legitimidad interna en la decisión de expulsar fuera de sí mismo todo lo que no es de agrado del yo placer: es el caso del hermano, indeseable: "La agresividad es una tendencia o conjunto de tendencias que se actualizan en conductas reales o fantasmáticas dirigidas a dañar a otro, a destruirlo" (Laplanche \& Pontalis, 1983, p. 12).

Toda relación queda trazada por la sombra de la muerte y la agresividad como el modo de presentación de la pulsión de muerte, siendo así, la agresión es la heredera legítima de la pulsión de muerte, lo que anima el conflicto es la competencia por la posesión común, por lo tanto, en este primer fratricidio la pulsión de muerte encuentra una vía directa de satisfacción sobre el objeto, viabilizando el odio directo hacia el hermano al ocasionarle la muerte; ante tal desenlace no hay posibilidad de establecer los llamados lazos sociales.

\section{Los afrontados hermanos: Caín y Abel}

Hobbes (como se citó en Trías, 2005) mencionó que "en el comienzo de la historia hay siempre una relación fraterna. Eso sí, teñida de sangre, marcada por un acto inaugural: la vio- lencia" (p. 45), en este mismo texto, en páginas siguientes, Hobbes afirma que es "el crimen fratricida, parricida, homicida, filicida a partir del cual se establece la relación inaugural de unos con otros" (p. 50). El odio no sólo es con inesperada regularidad el acompañante del amor, como es atestiguado por la ambivalencia, en las más diversas circunstancias el odio se muda en amor y viceversa.

Freud (1916-17/1990) describe que ante la llegada de un hermano, la situación de idealización, de autoridad, seguidas de la identificación con el de su propio sexo, entrarán en crisis y se transformarán en otras. El nacimiento de un hermano será un motivo para introducir elementos hostiles en el vínculo del niño con sus padres, éstos iniciarían un movimiento de desvalorización de los padres junto a la aparición de sentimientos en el hijo sobre no ser suficientemente querido.

Muy en particular son los niños nacidos después que otros hermanos quienes mediante esas imaginerías arrebatan la primacía sobre todo a los predecesores (exactamente como en las intrigas que registra la historia). Se comprende que, el nivel al que me estoy refiriendo ahora, la novela está al servicio de "eliminar" de un plumazo a los rivales. (Génoves, 2004, p. 6).

¿Por qué Caín mató a Abel?, es la pregunta que más debiera interesar aclarar. Caín amaba a su padre, lo admiraba, tal vez porque ellos tenían algo que Caín quería tener, tenía que ser algo que lo hiciera igual a ellos, que se identificara con él aún más, algo como... ¡la similitud 
del nombre! (Adán-Caín-Abel). ¿Tienen algún parecido? ¿Es acaso que Adán y Abel son parecidos porque en su nombre tienen la misma inicial y Caín ha sido marcado desde su nacimiento como diferente? Luego entonces, no se puede dejar de lado la similitud que existe entre Adán y Caín: los dos son primogénitos y Abel es el rival que quiere tomar el lugar de Caín en la familia. Así es que por tales motivos inconscientes se inicia una rivalidad entre los varones, aunque sea muy temerario asegurar tal cosa, pues las frases que denotan tal argumento pudieran ser una trampa o una rampa de acceso a un nuevo saber que se complejiza más al ser abordado.

La agresión más que la causa de la no satisfacción pulsional surgiría cuando el yo sufre dicha herida narcisista, infringida por el obstáculo en cuestión. "Así, la agresión a otras personas puede entenderse como un medio para no dirigirla contra uno mismo... el sujeto se halla ante la alternativa de ser violento con otras personas o autodestruirse" (Melero, 1996, p. 24).

La intrusión del otro está marcada por el acontecimiento de la llegada, por consiguiente, el recién nacido constituye un peligro, así pues el dichoso acontecimiento de las familias revela ser una mala noticia para el interesado: ese hijo único convertido de la noche a la mañana en el hijo mayor; el hermano, en efecto, es una contrariedad, y esa es la fuente del deseo de muerte.

Propietario de la casa, poseedor de sus llaves, reaccionará frente a quien viene a incorporarse a ella con el rigor del rechazo. El hecho de quedar así colocado en segunda línea puede inscribirse como una pesada amargura. La píldora puede ser tan amarga que la vida ya no tendrá nunca la dulzura de antaño. Por eso se apunta y se increpa a los padres, fundamentalmente a la madre: ¿por qué me hiciste esa jugada? (Assoun, 2000, p. 27).

El hecho de que el pequeño egoísta puedo expresar su odio en voz alta hacia el recién llegado confirma que habla con la voz tonante de la legitimidad de la defensa de sí mismo y lo estorban menos que en el contencioso edípico las reservas de la culpa. La relación parental afecta de entrada la represión; la relación de la familia, por su parte, la autoafirmación y la autoconservación. Lo que se plantea es una cuestión de defensa de la propiedad frente al extraño, ya que advertirá la problemática espacial del asunto de la rivalidad fraterna: lucha por el territorio frente al invasor. Después se tratará de la posesión de objetos favoritos de los que no quiere despojarse, desprenderse, bajo ningún precio, en beneficio del recién llegado porque es vital conservar un objeto propio.

\section{Los mellizos elegidos: Esaú y Jacob}

La segunda efigie es la Rivalidad Fraterna Tolerada tiene relación con el papel de la conciliación de su hostilidad.

El relato bíblico de los hermanos Esaú y Jacob hace referencia sobre el embarazo de Rebeca su madre, alude a los disturbios físicos $\mathrm{y}$ emocionales; por tal situación ella procede como todos sus semejantes de la época a consultar a Yahvé —en la nación hebrea la consulta a Jehová se hacía por lo regular a través de profetas o sacerdote en los santuarios 
o lugares de adoración y sacrificios - en la respuesta de Dios a Rebeca le declara: hay dos hijos en tu vientre — confirmando el conflicto entre los no nacidos todavía y anunciando tres realidades para el futuro-. (Valera, 2009, p. 30).

Es decir, los malestares que Rebeca sentía desde la matriz auguraban el conflicto constante en el que estarían inmersos los futuros hijos de Israel, debido a que el desarrollo de ambos pueblos sería diferente; asimismo, se predice que uno de ellos será mayor y más fuerte que el otro y, también, que el hijo mayor servirá al menor, al contrario de lo que dicta el derecho de la primogenitura.

La narración prevé, además, que al crecer los niños fueron de vocación y carácter muy diferentes: Esaú era cazador del campo, Jacob de la casa. Sin lugar a dudas existía entre ellos una competencia continua por el favoritismo de sus padres: Jacob preferido de su madre y Esaú preferido del padre. Se puede visualizar de manera más clara su rivalidad en dos momentos: el primero en la venta de la primogenitura y el segundo en el robo de la bendición patriarcal.

Los hermanos se encontraban en una situación especial, Jacob había preparado un guisado y Esaú había vuelto del campo, posiblemente de un intento de caza sin logro; llegó cansado y quiso comer ese guiso rojo. Así, Jacob aprovechó la oportunidad y pidió comprar la primogenitura. Ambos hermanos conocían muy bien el significado de la primogenitura en su contexto cultural: "Jacob deseaba piadosamente la primogenitura... 1. Escogió el tiempo más apto.
2. Hecho ya el trato se aseguró de que quedara firme con el juramento de Esaú" (Mattew, 1983, p. 171).

El segundo momento fue el engaño de Jacob, al hacerse pasar por su hermano para que le fuera otorgada la bendición paterna; el engaño no resultó fácil, Isaac tuvo varias dudas y objeciones a Jacob y este magistralmente satisfizo todas ellas; la reacción de Esaú se manifestó pronto y su plan de venganza se hizo público. La decisión fue matar a Jacob, entonces, la descendencia quedó en abierto peligro por el riesgo de extinción de un descendiente y la anulación del otro por la culpabilidad del homicidio.

No necesariamente el niño pequeño ama a sus hermanos, y a menudo es evidente que no lo hace. Es indudable que los odia como a sus competidores, y sabemos bien que con frecuencia esa actitud se mantiene por largos años hasta la época de la madurez. (Freud, 1915-16/1990, p. 187).

La historia misma testifica el cumplimiento en el desarrollo del pueblo de Edom (hoy Jordania), y su relación con Israel. La herencia fue resuelta pero "continúa en hostilidad, separación y finalmente reconciliación" (Mattew, 1983, p. 161).

A partir de ese momento, se evidenció el drama de los celos, se identificó también con la madre devorada por el hermano menor, y la ruina de la situación omnipotente que tenía. Lo que pretendía era eliminar al rival, pero eliminarlo significaba eliminarse, entonces, su objeto rival podía llegar a cautivarlo y convertir el odio en un amor fraterno. "En el momento de nacer 
un hermano... el niño dedica al intruso, al rival un odio celoso" (Le Guen, 1974, p. 28). Si no es trasmudado el odio en amor se puede llegar a matar al ser amado.

Lacan (1977) destacaba que los celos ocupan un lugar prioritario en la relación entre pares o hermanos, estos celos debían comprenderse, suscritos por las vicisitudes de la identificación y no por una rivalidad, "los celos en su base, no representan una rivalidad vital, sino una identificación mental” (p. 30). Tal circunstancia, según el mismo Lacan, permite esclarecer el papel de los celos en la génesis de la sociabilidad.

Para Freud (1921/1990), los celos normales están compuestos por el duelo, el dolor por el objeto de amor que se cree perdido y por la afrenta narcisista, además por sentimientos de hostilidad hacia los rivales. Nacen en el seno de relaciones actuales y retoman las más tempranas mociones de la afectividad infantil y brotan del complejo de Edipo o del complejo de los hermanos del primer periodo sexual.

Los celos provocan actitudes intensamente hostiles y agresivas hacia los hermanos, que podrían extremarse hasta desearles la muerte, pero sucumben en el proceso de desarrollo, donde bajo los influjos de la educación y la continua impotencia se llega a la represión y a una transmutación de sentimientos de identificación tiernos. Esto es, por consecuencia el origen de las pulsiones sociales. Minsky (2000) menciona que en una situación de rivalidad entre hermanos, "las poderosas emociones tienen a menudo una característica de obstinación que gira más en torno a los ejes pérdida/ganancia, vergüenza/ culpa, víctima/vencedor” (p. 209).
La fraternidad está sellada de entrada para Lacan (1977), traumáticamente, por la intrusión de un semejante, así la identificación mental implica entre los sujetos una cierta adaptación de las posturas y de los gestos; en la medida misma de esta adaptación, es posible considerar que desde ese estudio se bosqueja el reconocimiento de un rival, es decir, de otro como objeto. Dicho nuevo objeto conmueve la fascinación dual imaginaria, ya que este proceso no solamente indica que el sujeto adopta como suyos uno o más atributos de otro sujeto, sino que se refiere a "la transformación que se produce en el sujeto cuando asume una imagen" (Evans, 1997, p. 108), la reconoce y se apropia de ella como si fuera él mismo.

La doctrina del psicoanálisis permite aprehender el problema con mayor profundidad, nos muestra en el hermano, en el sentido neutro, al objeto electivo de las exigencias de la libido que, en el estadio que estudiamos, son homosexuales. Pero insiste acerca de la confusión de este objeto de dos relaciones afectivas, amor e identificación. (Lacan, 1977, p. 32).

La última parte del relato bíblico trata sobre el regreso de Jacob a Canaán, después de varios años de vivir en el exilio enfrentó a su hermano, a quien había engañado veinte años antes, por lo tanto, Jacob tomó la iniciativa del reencuentro. El viaje no se realizó con facilidad, pues se tenía que superar la distancia y el peligro de los pobladores locales.

Para realizar el encuentro con su hermano preparó un modelo de estrategia de protección y utilizó una acción preparatoria: enviar mensa- 
jeros a Esaú con el fin de adelantarse y prevenir cualquier acto destructivo; los mensajeros regresaron diciendo que Esaú venía a su encuentro con cuatrocientos hombres, lo cual causó angustia y temor en Jacob, ya que años antes había experimentado angustia ante el engaño a su padre y reactivó dicho sentimiento ante su hermano.

Freud (1925-26/1990) señala que la angustia del nacimiento es el modelo de todas las situaciones de peligro y siempre tendrá como referente la situación de separación de la madre, por lo tanto, la angustia nace como reacción ante el peligro primeramente por la pérdida del objeto, es decir, la madre, pero no es con precisión la pérdida de la madre lo que activa la angustia en el niño sino ante una necesidad que la madre tiene que satisfacer; esta circunstancia se convierte en una situación traumática, o bien, en una situación de peligro. Al encontrarse solo y descubrir un rostro ajeno despierta la añoranza de la madre. El sujeto no puede gobernar esta excitación, en cambio, la muda en angustia, entonces, la presencia de un tercero provoca la angustia.

Ante esta angustia, Jacob utilizó una segunda estrategia, dividió el campamento en dos con la prevención de que si uno fuese atacado, el otro pudiera sobrevivir. Envió a Esaú sucesivamente varios y significativos presentes como señal de cortesía y homenaje a un gran personaje, según sus costumbres. En su encuentro con Esaú, los siervos debían decir que era un presente a Esaú de su siervo Jacob y que éste venía detrás para su encuentro.

Además, explota al máximo las debilidades humanas de Esaú: el deseo de superioridad y riqueza material inmediata. Todo esto es reminiscente de la compra de la primogenitura. El propósito último era el de buscar apaciguar la ira de Esaú y encontrar la reconciliación para asegurar el futuro. (Carro, Poe, \& Zorzoli, 2005, p. 185).

El hijo mayor suele ser identificado como el destinado a prolongar la progenie y fusionarse con la identidad del padre; esta identificación es inmediata, directa y especular. Asimismo, tal situación es reforzada con el recelo, legitimidad y excesiva responsabilidad por el propio hermano mayor al interceptar en el menor el acceso identificatorio con las figuras parentales. Se evidencia en él un recelo en cuanto a no ser cuestionado en su exclusivo lugar como el supuesto único y privilegiado heredero ante los siguientes hermanos usurpadores.

El hijo mayor se encuentra programado como aquél que llega al mundo para restañar las heridas narcisistas del padre y para completarlo, y el menor, para nivelar el equilibrio del sistema narcisista materno. La experiencia psicoanalítica nos enseña que la rígida división del "botín de los hijos", ofrendados como meros objetos para regular la estabilidad psíquica de la pareja parental, es punto de severas perturbaciones en la plasmación de la identidad sexual y en el despliegue de los procesos sublimatorios en cada uno y entre los hermanos. (Kancyper, 2002, p. 8).

El hermano menor exige un recorrido identificatorio más complicado para el logro de su identidad sexual, porque, por un lado, permanece excluido de un disponible lugar identificatorio con los progenitores y suele llegar a bus- 
car nuevas alternativas, lo más alejadas posible del territorio de la economía libidinal familiar, donde el hermano mayor permanece investido como el legítimo heredero, o el reconocido doble, a través del mayorazgo; mientras él suele ser el cuestionador y el creador, el primogénito, en cambio, es el conservador.

No sé por qué suponemos que ha de ser amable, pues los ejemplos de hostilidad entre hermanos ya adultos se imponen a la experiencia de todos nosotros y hartas veces podemos comprobar que esa desavenencia viene de la niñez o existió desde siempre. Pero aun muchísimos adultos que hoy sienten tierno apego por sus hermanos $\mathrm{y}$ los asisten, vivieron con ellos en la infancia una hostilidad apenas interrumpida. El niño mayor maltrató al menor, lo denigró, le quitó sus juguetes; el menor se consumió en furia impotente contra el mayor, lo envidió y lo temió, o enderezó contra el opresor sus primeros conatos de libertad y de conciencia de lo justo. Los padres dicen que sus hijos no se soportan, y no atinan a descubrir la razón. (Freud, 1900/1990, p. 260).

La agresividad no sólo puede externarse con la descarga de la tensión o su incremento si no es liberada; no podemos encontrar una pauta común, el hombre ayuda a su propia destrucción, al enfrentarse a una forma de vida que parece no tener escapatoria.

El encuentro es inminente. Jacob visualizó a Esaú su hermano con sus cuatrocientos hombres, entonces, preparó la última estrategia para evitar una destrucción familiar total.
Estableció tres grupos y dispuso a sus hijos con sus respectivas madres en orden de estimación: primero y en la posición más vulnerable, las siervas y sus respectivos hijos. En el segundo grupo, a Lea y sus hijos. Y al final, junto a él, a Raquel y su hijo José, quien era para Jacob en ese momento lo más preciado. Jacob se acercó con mucho respeto y humildad especial a Esaú, inclinándose ante él siete veces: "La reacción de Esaú es totalmente opuesta a la de Jacob: corre, le abraza y le besa" (Carro et al., 2005, p. 189), estas acciones reflejan afecto, perdón y reconocimiento de hermandad.

A partir del modelo anterior se puede vislumbrar un aplazamiento de la rivalidad fraterna, es decir, existe una aparente reconciliación entre los hermanos, se llega a tolerar la rivalidad como un asunto conciliatorio, el hecho es que tienen que vivir separados. El mismo Jacob le pide que se adelante y dice que él le seguirá, así escoge un lugar alejado de su hermano para establecer su residencia.

En "Psicología de las masas y análisis del yo" (1921/1990), Freud pone de manifiesto, a partir del mito de la horda primitiva y de los cuentos populares, la hazaña heroica asumida por el hijo menor para separarse de la masa. Asimismo, "es frecuente que el héroe debe resolver una tarea difícil-casi siempre se trata del hijo menor, y no rara vez uno que ha pasado por tonto, vale decir por inofensivo" (p. 129).

El hermano es adoptado porque ya no constituye para el sujeto el obstáculo o el reflejo, sino es considerado una persona digna de amor; las pulsiones agresivas se subliman en ternura. 
Por lo tanto, la imago fraterna es lo contencioso edípico, al tiempo que posibilita lo que puede llamarse socialización del narcisismo, dado que el dibujo de lo especular permite fijar lo fraterno.

Lo que se dibuja desde el tránsito de la expulsión es la relación íntima con el doble, es decir, con el hermano; el doble no es más que una forma de alteridad en el espejo, en esa confusión donde el yo cree extinguirse, al tomar la presa del yo por la sombra del doble, pone en acto, sin duda, ese cuerpo a cuerpo con el doble.

Esta efigie constituye un reflejo de la rivalidad fraterna tolerada, en el sentido que es introducido el hermano en el drama de los celos. Es posible considerar que en este drama se bosqueje el reconocimiento del rival, e implique la adopción de uno o más atributos al identificarse con él.

\section{La historia de José, hijo del patriarca Israel}

La tercera y última efigie trata sobre la declinación de la rivalidad fraterna. Sirve de punta de lanza en relación con la forma cómo el protagonista pudo llegar después de muchas vicisitudes a fraternizar con sus hermanos, y establecer lazos sociales perdurables.

El primer problema de la unidad familiar se da por los conflictos de José con sus hermanos, varias son las a causas que se agravan con el tiempo. La historia relata que José era el hombre de confianza de su padre, por tal motivo, Jacob mostraba de manera visible y determinante su preferencia; tal vez el hecho de haber amado a su madre más que a ninguna de sus otras mujeres fue un papel importante, luego entonces ser huérfano de madre lo hacía vulnerable. La distinción de la túnica con diversos colores era señal de privilegio y posición jerárquica en la familia, ya que era la ropa propia de un príncipe elegido para reinar.

Para la eliminación de José se tramaron varios planes: matarlo, tirarlo en una cisterna y culpar de la muerte a una fiera. Rubén sugiere dejarlo en la cisterna, como hijo primogénito sentía la responsabilidad de librarlo de la muerte y llevarlo de vuelta a casa, o tal vez de convertirse en héroe ante su padre, después de haber querido usurpar el lugar del patriarca.

En la relación familiar, el sentimiento de pertenencia se hace presente de alguna $u$ otra forma en aras del bien común, lo que denuncia, al menos, una raíz en la renuncia narcisista en dicho sentimiento. El mandato bíblico es aún más exigente, pide amar al prójimo más que a sí mismo y el orden social, en ocasiones, suele aumentar la apuesta cuando prescribe la pretensión de no albergar sentimientos hostiles. Aunque dicho odio que debiera ser desterrado de lo fraterno reaparece una y otra vez; la unión es reclamada si no como sublime, al menos como ventajosa, en otros momentos esa mansedumbre de las relaciones sociales sólo es concebible como la única salida posible.

Si bien puede hablarse de reconciliación de los hermanos, como eco de la reconciliación con el padre, ésta sigue estando marcada con el sello de la ambivalencia: la reconciliación con el padre es posterior al asesinato simbólico. En el caso del lazo fraterno, debe pensarse el efecto inverso: la reconciliación se produce para evitar el asesinato y el odio fratricida debe leerse 
donde se desencadena como rompimiento de la ligazón, dicho de otra manera, el desbaratamiento de la agresividad.

El trabajo intenso del hermano que se puso de relieve sugiere que hay efectivamente una "imago del hermano", sin embargo, Freud tiene la precaución de recordar que la transferencia no está ligada a este modelo que es la "imago del padre" pero puede ser también efecto de la "imago de la madre" o del hermano (Assoun, 2000, p. 97).

La fórmula es violenta: no se conforma con recordar la fuerza de esa hostilidad de uno hacia el otro, sino que sugiere ya el carácter inagotable y en cierta forma inextinguible de esa sed de revancha. El menor también tiene hostilidad de sobra con respecto al hermano mayor y esa energía va a hacer mover, justamente, su incansable actividad, a la que dará su incomparable redoble.

Esta avidez competitiva en la que el derecho de mayorazgo se respeta con un temor sagrado daría, en efecto, la clave de ese vigor precoz; el hermano es el primer enemigo, aunque pero según la lógica de la sucesión familiar eso mismo empuja a un amor singular. El rival odiado se convierte en un ser amado, es decir, el odio excesivo termina por transformarse en amor, no sólo hay que desembarazarse de ese hermano, sino también serlo, convertirse en él.

La reconciliación se refiere a un lazo susceptible de transformarse y a una situación que involucra la noción de tiempo; se refiere, sin duda, a los vínculos que unen a los miembros de la familia, ya que con el crecimiento de los hermanos la actitud entre ellos experimenta transformaciones importantes. Los procesos de reconciliación con el hermano nos ponen sobre la pista de un destino fundamental del vínculo fraterno, que no es otro que el lazo social. Es preciso que reorientemos el ángulo de visión, ya no es cuestión de captar el surgimiento del otro, pero no hay que engañarse: la violencia reprimida reclama su parte.

Freud da la clave en su observación de que la pulsión llamada social, lejos de ser meramente innata, se desarrolla en el individuo infantil como formación reactiva ante las actitudes de rivalidad hostiles y en consecuencia se sienta sobre una manera particular de identificación con el otro. (Assoun, 2000, p. 107).

La apuesta de la relación fraterna se indica como un nexo de la agresividad y la identificación; en otros términos, la rivalidad vital está subordinada a la identificación mental, lo cual significa que no puede odiar a su hermano sino que se identifica con él, o mejor, si no confunde su imagen con el malo que está en él, lo que procura alcanzar, en el límite mediante el crimen. La identificación con el hermano permite el desdoblamiento. Esto se demuestra en el fratricidio, donde el sujeto a través de otro golpea su propia imagen, para evitarlo, entonces, se apuesta a la reconciliación como la forma de establecer lazos sociales y declinar la rivalidad fraterna, en esta última efigie ejemplifica cómo José se enfrenta con sus hermanos y logra la reconciliación.

Habían pasado veinte años, José reconocía, no obstante, los trató con hostilidad durante el encuentro inicial; para lograr su propósito, José 
planeó un complot para apresar a Benjamín. "El hermano es el estandarte de una ética de fraternidad y, al mismo tiempo una reivindicación de lo irremplazable; de la singularidad" (Morales, 2003, p. 333). Convierte la rivalidad fraterna en un amor fraterno al utilizar un mecanismo que está en defensa del yo que es la formación reactiva. Los cambios de actitud de los hermanos de José, de reconocimiento, y el impacto conmovedor del discurso de Judá en defensa de Benjamín convencen intelectual y emotivamente a José de que las condiciones se han cumplido y que ha llegado el momento de identificarse plenamente con sus hermanos. "Se humillaron ante él confesaron su falta y pidieron perdón... José con gran dosis de compasión, le confirma su reconciliación y su afecto" (Mattew, 1983, p. 262).

Freud (1908/1990) en "La moral sexual cultural y la nerviosidad moderna", consideró que la cultura se edifica sobre la sofocación de pulsiones; el ser humano, al ceder un fragmento de su persona, que son las inclinaciones agresivas, da lugar al nacimiento de un patrimonio cultural común para la sociedad. De acuerdo con esta tesis, en la familia se mueve al sujeto a una renuncia progresiva en favor del desarrollo cultural, cuando los procesos de reconciliación con el hermano tienen un destino fundamental del vínculo fraterno: el lazo social.

Además, por largo tiempo no se observa en el niño nada de un instinto gregario o sentimiento de masa. Este se forma únicamente cuando los niños son muchos en una misma casa, y a partir de su relación con los padres; y se forma, en verdad, como reacción frente a la envidia incipiente con que el niño mayor recibe al más pequeño. Aquel, por celos, querría sin duda desalojar (verdrängen) al recién llegado, mantenerlo lejos de los padres y expropiarle todos sus derechos; pero en vista de que este niño - como todos los que vienen despuéses amado por los padres de igual modo, $\mathrm{y}$ por la imposibilidad de perseverar en su actitud hostil sin perjudicarse, es compelido a identificarse con los otros niños, y así se forma en la cuadrilla infantil un sentimiento de masa o de comunidad. (Freud, 1921/1990, pp. 113-114).

Esta última efigie de rivalidad declinada es la que posibilita que los hermanos mantengan una armonía entre ellos, debido a la forma de resolución donde se puede elaborar el reconocimiento del otro existe una reparación y existe un pacto de paz que es respetado, por tanto, se perpetúa la alianza fraterna.

\section{Conclusiones}

La descripción de estas efigies posibilita el análisis de la violencia fraterna y visualiza vías más óptimas para la resolución con el fin de evitar lo acotado por Trías (2005) sobre:

1. La destrucción de ambos contendientes como sucedió con Polinice y Eteocles.

2. La destrucción de uno de ellos y el mantenimiento de vida de aquel que sobrevive: Caín y Abel.

3. La supervivencia de los dos, pero de forma desnivelada y desigual: Jacob y Esaú. José y sus hermanos. 
La primera y segunda forma tienen como consecuencia impedir el reconocimiento del semejante; y la tercera solución permite suponer que el sujeto percibe la actividad del otro, donde la identificación está presente y, por lo tanto, le suscita al sujeto emociones y posturas similares.

La referencia sobre la rivalidad consumada se debe a la relación fraterna que se establece entre hermanos que no llega a una resolución adecuada, es decir, un hermano aniquila al otro hermano o ambos se dan muerte e imposibilitan así que la relación fraterna pueda llegar a tener una identificación con el otro y se establezcan los lazos sociales. A la vez, el odio y los celos no son sublimados ni encarados, por el contrario, demandan que su descarga sea inmediata, así posibilitan la agresión contra el hermano, y como consecuencia después del acto fratricida no se presenta culpa ni arrepentimiento.

En cuanto a la rivalidad tolerada se advierte que en la relación fraterna existen ambivalencias de amor y odio que son conciliadas por los sujetos; en esta relación, los lazos sociales y la identificación con el otro se instauran, pero la hostilidad deja una huella permanente, ésta aflorará en algunas ocasiones y provocará que tal fraternidad se debilite. Existe tregua, pero también coexiste continuamente la amenaza de la lucha por el derrocamiento perpetrado, esa pugna complicará el establecimiento de los lazos sociales, los cuales serán fluctuantes.

La tercera efigie extraída de la historia de José, el hijo del patriarca Israel, es la rivalidad declinada, la cual es viable a través del proceso de identificación con el otro, o bien, la rivalidad fraterna que existe se convierte en una verdadera fraternidad, al establecer la reconciliación y dejar de lado lo individual para dar paso al sentido de igualdad entre sus semejantes y poseer lo mismo: el amor de sus padres.

Esta última efigie de rivalidad declinada posibilita que los hermanos mantengan una armonía entre ellos, debido a la forma de resolución donde se puede elaborar el reconocimiento del otro, existe una reparación y existe un pacto de paz que es respetado, por tanto, se perpetúa la alianza fraterna.

La importancia de las efigies radica en evitar la rivalidad consumada: salir victoriosos del deseo de muerte hacia el hermano y, a pesar de las luchas o conflictos con los hermanos, ser tolerante, para finalmente llegar a una relación fraterna en base en la reconciliación cuyo fin es posibilitar así la verdadera fraternidad.

Tal parece que la traducción es sencilla, fácil de soportar y de elaborar, sin embargo, se debe vislumbrar su trascendencia en el desarrollo de los llamados lazos sociales.

\section{Referencias}

Assoun, P. L. (2000). Lecciones psicoanalíticas sobre hermanos y hermanas. Buenos Aires: Nueva Visión.

Carro, D., Poe, T., \& Zorzoli, R. (2005). Comentario bíblico mundo hispano. Bogotá: Mundo Hispano.

Etimología. (2012.). Etimología de efigie. Recuperado de http:/etimologias.dechile.net/?efigie Evans, D. (1997). Diccionario introductorio del psicoanálisis lacaniano. México: Paidós. 
Freud, S. (1900/1990). Los sueños de la muerte de personas queridas. En Autor, La interpretación de los sueños (Vol. V). Buenos Aires: Amorrortu.

Freud, S. (1908/1990). La moral sexual "cultural" y la nerviosidad moderna. En Autor, El chiste y su relación con lo inconciente (Vol. VIII). Buenos Aires: Amorrortu.

Freud, S. (1915-16/1990). 13a conferencia. Rasgos arcaicos e infantilismo del sueño. En Autor, Conferencias de introducción al psicoanálisis (Vol. XV). Buenos Aires: Amorrortu.

Freud, S. (1916-17/1990). Doctrina general de las neurosis. En Autor, Conferencias de Introducción al psicoanálisis (Parte III, Vol. XVI). Buenos Aires: Amorrortu.

Freud, S. (1921/1990). Psicología de las masas y análisis del yo. En Autor, Más allá del principio del placer. Psicología de las masas $y$ análisis del yo y otras obras (Vol. XVIII). Buenos Aires: Amorrortu.

Freud, S. (1925-26/1990). Inhibición, síntoma y angustia. En Autor, Presentación autobiográfica, inhibición, síntoma y angustia, ¿Pueden los legos ejercer el análisis?, y otras obras (Vol. XX). Buenos Aires: Amorrortu.

Genovés, A. (2004). El mito del nacimiento del héroe. Madrid: Asociación Psicoanalítica de Madrid.

Kancyper, L. (2002). El Complejo Fraterno y sus cuatro funciones. México: Fepal.

Lacan, J. (1977). Estudios sobre la institución familiar. Buenos Aires: Zuto.

Laplanche, J., \& Pontalis, J. B. (1983). Diccionario de psicoanálisis. Barcelona: Labor.
Le Guen, C. (1974). El Edipo originario. Buenos Aires: Amorrortu.

Mattew, H. (1983). Pentateuco. España: Clie.

Melero, M. (1996). Conflictividad y violencia en los centros escolares. México: Siglo XXI.

Minsky, R. (2000). Psicoanálisis y cultura. Madrid: Cátedra.

Morales, H. (2003). Sujeto en el laberinto. México: Ediciones de la noche.

Trías, E. (2005). La política y su sombra. Barcelona: Anagrama.

Valera, R. (2009). Santa Biblia. Brasil: Sociedades bíblicas. 